\author{
A. V. Glushkov ${ }^{l}$, V. B. Ternovsky², A. V. Smirnov ${ }^{l}, A$. A. Svinarenko ${ }^{1}$ \\ ${ }^{1}$ Odessa State Environmental University, L’vovskaya str.15, Odessa, 65016 \\ ${ }^{2}$ Odessa National Maritime Academy, Didrikhsona str. 4, Odessa, 65001 \\ E-mail: glushkovav@gmail.com
}

\title{
GAUGE-INVARIANT RELATIVISTIC PERTURBATION THEORY APPROACH TO DETERMINATION OF ENERGY and SPECTRAL CHARACTERISTICS FOR HEAVY AND SUPERHEAVY ATOMS AND IONS: REVIEW
}

\begin{abstract}
We reviewed an effective consistent ab initio approach to relativistic calculation of the spectra for multi-electron heavy and superheavy ions with an account of relativistic, correlation, nuclear, radiative effects is presented. The method is based on the relativistic gauge-invariant (approximation to QED) perturbation theory (PT) and generalized effective field nuclear model with using the optimized one-quasiparticle representation firstly in theory of the hyperfine structure for relativistic atom. The wave function zeroth basis is found from the Dirac equation with potential, which includes the core ab initio potential, the electric and polarization potentials of a nucleus. The correlation corrections of the high orders are taken into account within the Green functions method (with the use of the Feynman diagram's technique). There have taken into account all correlation corrections of the second order and dominated classes of the higher orders diagrams (electrons screening, particle-hole interaction, mass operator iterations). The magnetic inter-electron interaction is accounted in the lowest on $\alpha$ parameter ( $\alpha$ is the fine structure constant), approximation, the self-energy part of the Lamb shift is taken effectively into consideration within the Ivanov-Ivanova non-perturbative procedure, the Lamb shift polarization part - in the generalized Uehling-Serber approximation with accounting for the Källen-Sabry $\alpha^{2}(\alpha Z)$ and Wichmann-Kroll $\alpha(\alpha Z)^{\mathrm{n}}$ corrections.
\end{abstract}

\section{Introduction}

In last years a studying the spectra of heavy and superheavy elements atoms and ions is of a great interest for further development as atomic and nuclear theories (c.f.[1-8]). Theoretical methods used to calculate the spectroscopic characteristics of heavy and superheavy ions may be divided into three main groups: a) the multi-configuration Hartree-Fock method, in which relativistic effects are taken into account in the Pauli approximation, gives a rather rough approximation, which makes it possible to get only a qualitative idea on the spectra of heavy ions. b) The multiconfiguration Dirac-Fock (MCDF) approximation (the Desclaux program, Dirac package) $[1,2]$ is, within the last few years, the most reliable version of calculation for multielectron systems with a large nuclear charge; in these calculations oneand two-particle relativistic effects are taken into account practically precisely. The calculation program of Desclaux is compiled with proper account of the finiteness of the nucleus size; however, a detailed description of the method of their investigation of the role of the nucleus size is lacking. In the region of small $\mathrm{Z}$ ( $\mathrm{Z}$ is a charge of the nucleus) the calculation error in the MCDF approximation is connected mainly with incomplete inclusion of the correlation and exchange effects which are only weakly dependent on Z; c) In the study of lower states for ions with $Z \leq 40$ an expansion into double series of the PT on the parameters $1 / Z, \alpha Z$ ( $\alpha$ is the fine structure constant) turned out to be quite useful. It permits evaluation of relative contributions of the different expansion terms: non-relativistic, relativistic, QED contributions as the functions of $Z$. Nevertheless, the serious problems in calculation of the heavy elements spectra are connected with developing new, high exact methods of account for the QED effects, in particular, the Lamb shift (LS), self-energy (SE) part of the Lamb shift, vacuum polarization (VP) contribution, correction on the nuclear finite size for heavy elements and its account for different spectral properties, including calculating the energies and constants of the hyperfine structure, deriviatives of the 1-electron characteristics on nuclear 
radius, nuclear electric quadrupole, magnetic dipole moments etc (c.f.[1-98]).

In present paper we review an effective initio approach to relativistic calculation of the spectra for multi-electron superheavy ions with an account of relativistic, correlation, nuclear, radiative effects is presented. The method is based on the relativistic gauge-invariant (approximation to QED) perturbation theory (PT) and generalized relativistic dynamical effective field nuclear model with using the optimized one-quasiparticle representation in theory of the hyperfine structure for relativistic systems [15-60].

The correlation corrections of the high orders are taken into account within the Green functions method (with the use of the Feynman diagram's technique). There have taken into account all correlation corrections of the second order and dominated classes of the higher orders diagrams (electrons screening, particle-hole interaction, mass operator iterations) [2,60-99]. The magnetic interelectron interaction is accounted in the lowest on $\alpha^{2}$ parameter, the LS polarization part - in the Uehling-Serber approximation, self-energy part of the LS is accounted effectively within the Ivanov-Ivanova non-perturbative procedure [58]. The expressions for the energies and constants of the hyperfine structure, deriviatives of 1-electron characteristics on nuclear radius, nuclear electric quadrupole, magnetic dipole moments $Q$ etc are presented. As illustration some data for atom of hydrogen ${ }^{1} \mathrm{H}$ (test calculation) and superheavy $\mathrm{H}$-like ion with nuclear charge $\mathrm{Z}=170$, Lilike multicharged ions are listed.

\section{Gauge-invariant relativistic many-body perturbation theory method for heavy ions}

\subsection{General Formalism}

In atomic theory, a convenient field procedure is known for calculating the energy shifts $\Delta E$ of the degenerate states. Secular matrix $M$ diagonalization is used. In constructing $M$, the Gell-Mann and Low adiabatic formula for $\Delta E$ is used. A similar approach, using this formula with the QED scattering matrix, is applicable in the relativistic theory. In contrast to the non-relativistic case, the secular matrix elements are already complex in the PT second order (first order of the inter-electron interaction). Their imaginary parts relate to radiation decay (transition) probability. The total energy shift of the state is usually presented as follows:

$$
\begin{gathered}
\Delta E=\operatorname{Re} \Delta E+\mathrm{i} \operatorname{Im} \Delta E, \\
\operatorname{Im} \Delta E=-\Gamma / 2,
\end{gathered}
$$

where $\Gamma$ is interpreted as the level width, and the decay possibility $P=\Gamma$. The whole calculation of energies and decay probabilities of a non-degenerate excited state is reduced to calculation and diagonalization of the complex matrix $M$. To start with the Gell-Mann and Low formula it is necessary to choose the PT zero-order approximation. Usually, the one-electron Hamiltonian is used, with a central potential that can be treated as a bare potential in the formally exact QED PT. There are many well-known attempts to find the fundamental optimization principle for construction of the bare one-electron Hamiltonian (for free atom or atom in a field) or (what is the same) for the set of one-quasiparticle (QP) functions, which represent such a Hamiltonian [1-8]. As the bare potential, one usually includes the electric nuclear potential $\mathrm{V}_{\mathrm{N}}$ and some parameterized screening potential $\mathrm{V}_{\mathrm{C}}$. The parameters of the bare potential may be chosen to generate the accurate eigen-energies of all many-QP states. In the PT second order the energy shift is expressed in terms of the two-QP matrix elements [6-8]:

$$
\begin{aligned}
& V(1,2 ; 4,3)=\sqrt{\left(2 \mathrm{j}_{1}+1\right)\left(2 \mathrm{j}_{2}+1\right)\left(2 \mathrm{j}_{3}+1\right)\left(2 \mathrm{j}_{4}+1\right)} .
\end{aligned}
$$

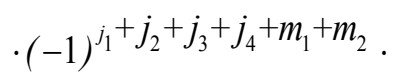

$$
\begin{aligned}
& \times \sum_{\lambda, v}(-1)^{v}\left[\begin{array}{l}
j_{1} \ldots . . j_{3} \ldots \lambda \\
m_{1} .-m_{3} . . v
\end{array}\right]\left[\begin{array}{l}
j_{2} \ldots . . j_{4} \ldots \lambda \\
m_{2} . . m_{4} . . v
\end{array}\right]\left(Q_{\lambda}^{Q u l}+Q_{\lambda}^{B r}\right) \text {. }
\end{aligned}
$$

Here $Q_{\lambda}^{\mathrm{Qul}}$ is corresponding to the Coulomb part of interaction $\left(Q_{\lambda}^{B}\right.$-Breit part) :

$$
\begin{aligned}
& Q_{\lambda}^{Q u l}=\left\{R_{\lambda}(1243) S_{\lambda}(1243)+R_{\lambda}(\widetilde{1} 24 \widetilde{3}) S_{\lambda}(\widetilde{1} 24\right. \\
& \left.+R_{\lambda}(1 \widetilde{2} \widetilde{4} 3) S_{\lambda}(1 \widetilde{2} \widetilde{4} 3)+R_{\lambda}(\widetilde{1} \widetilde{2} \widetilde{4} \widetilde{3}) S_{\lambda}(\widetilde{1} \widetilde{2} \widetilde{4} \widetilde{3})\right\}
\end{aligned}
$$

where $R(1,2 ; 4,3)$ is the radial integral of the Coulomb inter-QP interaction with large radial Dirac components; the tilde denotes a small Dirac com- 
ponent; $S_{\alpha}$ is the angular multiplier (see details in Refs.[2-12]). To calculate all necessary matrix elements one must have the 1QP relativistic functions.

\subsection{The Dirac-Kohn-Sham Relativistic Wave Functions}

Usually, a multielectron atom is defined by a relativistic Dirac Hamiltonian( the a.u. used):

$$
H=\sum_{i} h\left(r_{i}\right)+\sum_{i>j} V\left(r_{i} r_{j}\right) .
$$

Here, $h(r)$ is one-particle Dirac Hamiltonian for electron in a field of the finite size nucleus and $V$ is potential of the inter-electron interaction. The relativistic inter electron potential is as follows $[7,8]$ :

$$
V\left(r_{i} r_{j}\right)=\exp \left(i \omega_{i j} r_{i j}\right) \cdot \frac{\left(1-\alpha_{i} \alpha_{j}\right)}{r_{i j}},
$$

where $\alpha_{i j}$ is the transition frequency; $\alpha_{i}, \alpha_{j}$ are the Dirac matrices. The Dirac equation potential includes the electric potential of a nucleus and exchange-correlation potential. One of the variants is the Kohn-Sham-like (KS) exchange relativistic potential, which is obtained from a Hamiltonian having a transverse vector potential describing the photons, is as follows [33]:

$$
\begin{gathered}
V_{X}[\rho(r), r]=V_{X}^{K S}(r) \cdot\left\{\frac{3}{2} \ln \frac{\left[\beta+\left(\beta^{2}+1\right)^{1 / 2}\right]}{\beta\left(\beta^{2}+1\right)^{1 / 2}}-\frac{1}{2}\right\}, \\
\beta=\left[3 \pi^{2} \rho(r)\right]^{1 / 3} / c
\end{gathered}
$$

The corresponding correlation functional is $[2,33]$ :

$$
V_{C}[\rho(r), r]=-0.0333 \cdot b \cdot \ln \left[1+18.3768 \cdot \rho(r)^{1 / 3}\right],
$$

where $b$ is the optimization parameter (see details in Refs. $[2-4,9,10])$.

One-particle wave functions are found from solution of the Dirac equation, which is written in the known two-component form:

$$
\begin{aligned}
& \frac{\partial F}{\partial r}+(1+\chi) \frac{F}{r}-(\varepsilon+m-v) G=0 \\
& \frac{\partial G}{\partial r}+(1-\chi) \frac{G}{r}+(\varepsilon-m-v) F=0
\end{aligned}
$$

Here we put the fine structure constant $\alpha=1, \chi$ - the Dirac number. At large $\chi$ the radial func- tions $\mathrm{F}$ and $\mathrm{G}$ vary rapidly as:

$$
\begin{aligned}
& F(r), G(r) \approx r^{\gamma-1} \\
& \gamma=\sqrt{\chi^{2}-\alpha^{2} z^{2}}
\end{aligned}
$$

This involves difficulties in numerical integration of the equations for $r \rightarrow 0$. To prevent it, it is convenient to turn to new functions isolating main power dependence: $f=F^{1-|\chi|}, g=G^{1-|\chi|}$. The Dirac equation for $F$ and $G$ components are transformed as:

$$
\begin{aligned}
& f^{\prime}=-(\chi+|\chi|) f / r-\alpha Z V g-\left(\alpha Z E_{n \chi}+2 / \alpha Z\right) g \\
& g^{\prime}==(\chi-|\chi|) g / r-\alpha Z V f+\alpha Z E_{n \chi}
\end{aligned}
$$

Here the Coulomb units (C.u.) are used. In Coulomb units the atomic characteristics vary weakly with $\mathrm{Z} ; E_{n}$ is one-electron energy without the rest energy. The boundary values of the correct solution are as:

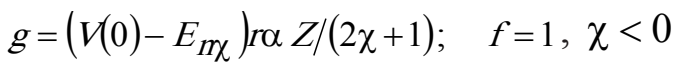

$f=\left(V(0)-E_{I \chi \chi}-2 / \alpha^{2} Z^{2}\right) \alpha Z ; \quad g=1, \chi>0$

The condition $f, g \rightarrow 0$ at $\mathrm{r} \rightarrow \infty$ determines the quantified energies $E_{n}$. The asymptotics of $f, g$ at $r \rightarrow \infty$ are: $f, g \sim \exp \left(-r / n^{*}\right)$ with effective quantum number $n^{*}=\sqrt{1 / 2\left|E_{17 \chi}\right|}$.

\subsection{Nuclear potential and charge density}

Earlier there are calculated some characteristics of hydrogen-like ions with the nucleus in the form of a uniformly charged sphere; analogous calculations by means of an improved model were also made [2-8]. As in refs. [33-35] we use the relativistic mean-field (RMF) approach, which is an effective field theory for nuclei below an energy scale of $1 \mathrm{GeV}$, separating the long- and intermediate-range nuclear physics from shortdistance physics, involving, i.e., short-range correlations, nucleon form factors, vacuum polarization etc, which is absorbed into various terms and coupling constants. Usually one starts with a Lagrangian density describing Dirac spinor nucleons interacting via meson and photon fields. This leads then to the Dirac equation with the potential terms describing the nucleon dynamics and the Klein-Gordon-type equations involving nucleon- 
ic currents and densities as source terms for mesons and the photon. In our approach we usually use the NL3-NLC (see details in refs. [33,38]), which is among the most successful parameterizations available. The resulted charge density is defined as:

$$
\rho_{c}(R)=A \int d x \exp [-\mu(R-x)] \rho_{p}(x),
$$

with the proton density $\rho_{p}$ constructed from the $\operatorname{RMF}(A, \mu$ are the numerical coefficients $)$ and normalized to the charge number Z:

$$
\int d R \rho_{p}(r)=Z \text {. }
$$

All corresponding model parameters are explained and given in refs. [33]. Another effective model approach to determine nuclear potential (the nuclear density distribution) is given by the known Fermi model. This model gives the following definition of the charge distribution $\rho(r)$ :

$$
\left.\tilde{n}(r)=\tilde{n}_{0} /\{1+\exp [(r-c) / a)]\right\},
$$

where the parameter $a=0.523 \mathrm{fm}$; the parameter $c$ is chosen by such a way that it is true the following condition for average-squared radius:

$$
\left.<r^{2}\right\rangle^{1 / 2}=\left(0.836 \cdot A^{1 / 3}+0.5700\right) \mathrm{fm} .
$$

We assume it as some zeroth approximation. Further the derivatives of various characteristics on $\mathrm{R}$ are calculated. They describe the interaction of the nucleus with outer electron; this permits recalculation of results, when $\mathrm{R}$ varies within reasonable limits. The Coulomb potential for the spherically symmetric density $\rho(r \mid R)$ is:

$$
V_{\text {nucl }}(r \mid R)=-\left((1 / r) \int_{0}^{r} d r^{\prime} r^{2} \rho\left(r^{\prime} \mid R\right)+\int_{r}^{\infty} d r^{\prime} r^{\prime} \rho\left(r^{\prime} \mid R\right)(17)\right.
$$

It is determined by the following system of differential equations $[7,8]$ :

$$
\begin{aligned}
& V^{\prime} \operatorname{nucl}(r, R)=\left(1 / r^{2}\right) \int_{0}^{r} \boldsymbol{d}^{\prime} r^{2} \rho\left(r^{\prime}, R\right) \equiv\left(1 / r^{2}\right) y(r, R) \\
& \begin{aligned}
y^{\prime}(r, R)= & r^{2} \rho(r, R), \\
& \rho^{\prime}(r, R)=-8 \gamma^{5 / 2} r / \sqrt{\pi} \exp \left(-\gamma r^{2}\right)= \\
& =-2 \gamma r \rho(r, R)=-\frac{8 r}{\pi r^{2}} \rho(r, R)
\end{aligned}
\end{aligned}
$$

with the corresponding boundary conditions.
2.4. QED corrections: Self-energy part of the Lamb shift and vacuum polarization correction

Procedure for an account of the radiative QED corrections is in details given in the refs. [24,8,33-35]. Regarding the vacuum polarization effect let us note that this effect is usually taken into account in the first PT theory order by means of the Uehling-Serber potential. This potential is usually written as follows (c.f.[2]):

$$
\begin{gathered}
U(r)=-\frac{2 \alpha}{3 \pi r} \int_{1}^{\infty} d t \exp (-2 r t / \alpha Z) \\
\left(1+1 / 2 t^{2}\right) \frac{\sqrt{t^{2}-1}}{t^{2}} \equiv-\frac{2 \alpha}{3 \pi r} C(g),
\end{gathered}
$$

where $g=r / \alpha Z$. In calculation [7-9] it has been used more exact approach. The Uehling-Serber potential, determined as a quadrature (19) may be approximated with high precision by a simple analytical function. The use of new approximation of the Uehling-Serber potential permits one to decrease the calculation errors for this term down to $0.5-1 \%$. It allows accounting for the Källen-Sabry $\alpha^{2}(\alpha Z)$ and Wichmann-Kroll $\alpha(\alpha Z)$ ${ }^{\mathrm{n}}$ corrections [33-35]. Besides, using a simple analytical function form for approximating the Uehling-Serber potential allows its easy inclusion into the general system of differential equations. This system includes also the Dirac equations and the equations for matrix elements. A method for calculation of the self-energy part of the Lamb shift is based on an idea by IvanovIvanova (c.f. $[7,8])$. In an atomic system the radiative shift and the relativistic part of the energy are, in. principle, determined by one and the same physical field. It may be supposed that there exists some universal function that connects the self-energy (SE) correction and the relativistic energy. The SE correction for the states of a hydrogen-like ion was presented by Mohr as:

$$
E_{S E}(H \mid Z, n l j)=0.027148 \frac{Z^{4}}{n^{3}} F(H \mid Z, n l j)
$$

The values of $F$ are given at $Z=10-110$, $n l j=1 s, 2 s, 2 p_{1 / 2}, 2 p_{3 / 2}$. These results are modified here for the states $1 s^{2} n l j$ of Li-like ions. It is supposed that for any ion with $n l j$ electron over the core of closed shells the sought value may be presented in the form:

$$
E_{S E}(Z, n l j)=0.027148 \frac{\xi^{4}}{n^{3}} f(\xi, n l j)\left(\mathrm{cm}^{-1}\right)
$$


The parameter $\xi=\left(E_{R}\right)^{1 / 4}, E_{R}$ is the relativistic part of the bounding energy of the outer electron; the universal function $f(\xi, n l j)$ does not depend on the composition of the closed shells and the actual potential of the nucleus. The procedure of generalization for a case of Li-like ions with finite nucleus consists of the following steps $[2,8,35]$ :

1). Calculation of the values $E_{R}$ and $\xi$ for the states $n l j$ of $\mathrm{H}$-like ions with the point nucleus (in accordance with the Zommerfeld formula);

2). Construction of approximating function $f$ by the found reference $Z$ and the appropriate $F(\mathrm{H} \mid Z, n l j)$;

3). Calculation of $E_{\mathrm{R}}$ and $\xi$ for the states $n l j$ of $L i$-like ions with the finite nucleus;

4). Calculation of $E_{\mathrm{SE}}$ for the sought states. The energies of the states of Li-like ions are calculated twice: with a conventional constant of the fine structure $\alpha=1 / 137$ and $\alpha^{\prime}=\alpha / 10^{3}$. The results of latter calculation are considered as non-relativistic. This permitted isolation of $E_{R}, \xi$. The above extrapolation method is more justified than using the known expansion on $\alpha Z$ parameter.

\subsection{The hyperfine structure parameters}

Energies of quadruple $\left(W_{q}\right)$ and magnetic dipole $(W \mu)$ interactions to define a hyperfine structure (HFS) are calculated as $[32,35]$ :

$$
\begin{aligned}
& W_{q}=[\Delta+C(C+1)] B, \quad W \mu=0,5 A C, \\
& \Delta=-(4 / 3)(4 \chi-1)(I+1) /[i(I-1)(2 I-1)], \\
& C=F(F+1)-J(J+1)-I(I+1) .
\end{aligned}
$$

Here $I$ is a spin of nucleus, $F$ is a full momentum of system, $J$ is a full electron momentum. HFS constants are expressed through the standard radial integrals $[2,8,35]$ :

$$
\begin{gathered}
A=\left\{\left[(4,32587) 10^{-4} Z^{2} \chi g_{I}\right] /\left(4 \chi^{2}-1\right)\right\}(R A)_{-2}, \\
B=\left\{7.287810^{-7} Z^{3} Q /\left[\left(4 \chi^{2}-1\right) I(I-1)\right\}(R A)_{-3},\right.
\end{gathered}
$$

Here $g_{I}$ is the Lande factor, $Q$ is a quadruple momentum of nucleus (in Barn); radial integrals are defined as follows:

$$
\begin{gathered}
(R A)_{-2}=\int_{0}^{\infty} d r r^{2} F(r) G(r) U\left(1 / r^{2}, R\right), \\
(R A)_{-3}=\int_{0}^{\infty} d r r^{2}\left[F^{2}(r)+G^{2}(r)\right] U\left(1 / r^{3}, R\right) .
\end{gathered}
$$

For calculation of potentials of the hyperfine interaction $U\left(1 / r^{n}, R\right)$, we solve the following differential equations [7,8]: $U\left(1 / r^{n}, R\right)=-n y(r, R) / r^{n+1}$. The functions $d U\left(1 / r^{n}, R\right) / d R$ are can be found by similar way. To obtain the corresponding value of $Q$ one must combine the HFS constants data with the electric field gradient calculated in our approach too. The details of calculation are presented in $[11,14,17,18]$.

\subsection{Correlation effects and construction of} optimal 1-quasiparticle representation

The problem of the searching for the optimal one-electron representation is one of the oldest in the theory of multielectron atoms. One of the simplified recipes represents, for example, the DFT method (see [2,3]). Unfortunately, this method doesn't provide a regular refinement procedure in the case of the complicated atom with few quasiparticles (electrons or vacancies above a core of the closed electronic shells). We use the method $[9,10]$. For simplicity, let us consider now the one-quasiparticle atomic system. The multi-quasiparticle case doesn't contain principally new moments. In the lowest, second order, of the QED PT for the $\Delta E$ there is the only onequasiparticle Feynman diagram a (fig.1), contributing the $\operatorname{Im} \Delta E$ (the radiation decay width).

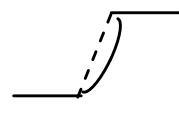

a

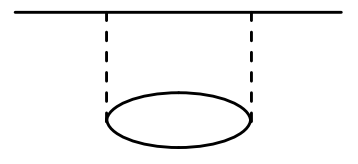

b

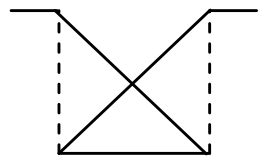

$\mathrm{c}$
Figure 1. a: second other PT diagram contributing the imaginary energy part related to the radiation transitions; b and c: fourth order QED polarization diagrams.

In the next, the fourth order there appear diagrams, whose contribution into the $\operatorname{Im} \Delta \mathrm{E}$ account for the core polarization effects. This 
contribution describes collective effects and it is dependent upon the electromagnetic potentials gauge (the gauge non-invariant contribution). We examine the multielectron atom with one quasiparticle in the first excited state, connected with the ground state by the radiation transition. In the PT zeroth approximation one can use the one-electron bare potential:

$$
V_{\mathrm{N}}(r)+V_{\mathrm{C}}(r),
$$

with $V_{\mathrm{N}}(r)$ describing the electric potential of the nucleus, $V_{C}(r)$, imitating the interaction of the with the core of closed shells. The perturbation in terms of the second quantization representation reads as

$$
-V_{\mathrm{C}}(r) \psi^{+}(r) \psi(r)-j_{\mu}(x) A^{\mu}(x) .
$$

The core potential $V_{\mathrm{C}}(r)$ is related to the core electron density $\rho_{C}(r)$ in a standard way. The latter fully defines the one electron representation. Moreover, all the results of the approximate calculations are the functionals of the density $\rho_{\mathrm{C}}(r)$. Here, the lowest order multielectron effects, in particular, the gauge dependent radiative contribution for the certain class of the photon propagator gauge is treating. This value is considered to be the typical representative of the electron correlation effects, whose minimization is a reasonable criteria in the searching for the optimal one-electron basis of the PT. Remember that the closeness of the radiation probabilities calculated with the alternative forms of the transition operator is commonly used as a criterion of the multielectron calculations quality. The imaginary part of the diagram a (fig.1) contribution has been presented previously as a sum of the partial contributions of $\alpha-s$ transitions from the initial state $\alpha$ to the final state $s[10]$ :

$$
\operatorname{Im} \Delta E_{\alpha}(\mathrm{a})=\sum_{S} \operatorname{Im} \Delta E(\alpha-s ; \mathrm{a}) .
$$

Two fourth order polarization diagrams $b, c$ (fig.1) should be considered further. The contributions being under consideration, are gaugedependent, though the results of the exact calculation of any physical quantity must be gauge independent. All the non-invariant terms are multielectron by their nature. Let us take the photon propagator calibration as usually:

$$
\begin{gathered}
D=D_{\mathrm{T}}+C D_{\mathrm{L}}, \\
D_{\mathrm{T}}=\delta_{\mu v} /\left(k_{0}^{2}-k^{2}\right), \\
D_{\mathrm{L}}=-k_{\mu} k_{v} /\left(k_{0}^{2}-k^{2}\right) .
\end{gathered}
$$

Here $C$ is the gauge constant; $D_{\mathrm{T}}$ represents the exchange of electrons by transverse photons, $D_{\mathrm{L}}$ that by longitudinal ones. One could calculate the contribution of the a,b,c diagrams (fig. 1) into the Im $\Delta E$ taking into account both the $D_{\mathrm{T}}$ and $D_{\mathrm{L}}$ parts. The a diagram (fig. 1 ) contribution into the $\operatorname{Im} \Delta E$ related to the $\alpha-s$ transition reads as

$$
\frac{1-\alpha_{1} \alpha_{2}}{r_{12}} \sin \left(\omega_{\alpha s} r_{12}\right) \psi_{\alpha}\left(r_{2}\right) \psi_{s}\left(r_{1}\right),
$$

for $D=D_{\mathrm{T}}$, and

$$
\begin{gathered}
-\frac{e^{2}}{8 \pi} \iint \mathrm{d} r_{1} \mathrm{~d} r_{2} \psi_{\alpha}^{+}\left(r_{1}\right) \psi_{s}^{+}\left(r_{2}\right)\left\{\left[\left(1-\alpha_{1} n_{12} .\right.\right.\right. \\
\left.\left.\cdot \alpha_{2} n_{12}\right) / r_{12}\right] \sin \left(\omega_{\alpha s} r_{12}\right)+\omega_{\alpha s} . \\
\left.\left(1+\alpha_{1} n_{12} \alpha_{2} n_{12}\right) \times \cos \left(\omega_{\alpha s} r_{12}\right)\right\} \psi_{\alpha}\left(r_{2}\right) \psi_{s}\left(r_{1}\right),
\end{gathered}
$$

for $D=D_{\mathrm{L}}$, where $\omega \alpha_{s}$ is the $\alpha-s$ transition energy. According to the Grant theorem, the $D \mu v_{\mathrm{L}}$ contribution vanishes, if the one-quasiparticle functions $\psi \alpha, \psi_{s}$ satisfy the same Dirac equation. Nevertheless this term is to be retained when using the distorted waves approximation, for example. Another very important example represents the formally exact approach based on the bare Hamiltonian defined by its spectrum without specifying its analytic form $[2,3]$. Here the noninvariant contribution appears already in the lowest order. When calculating the forth order contributions some approximations are inevitable. These approximations have been formulated in Refs.[10], where the polarization corrections to the state energies have been considered.

Let us consider the direct polarization diagram b (fig.1) as an example. The final expression for the sought value looks as

$$
\begin{aligned}
& \operatorname{Im} E_{\text {ninv }}\left(\alpha s \mid A_{d}\right)=-\frac{C e^{2}}{4 \pi} \iiint \int d r_{1} d r_{2} d r_{3} d r_{4} \sum\left(\frac{1}{\omega_{m n}+\omega_{\alpha_{s}}}+\right. \\
& \left.+\frac{1}{\omega_{m n}-\omega_{\alpha_{s}}}\right) \Psi_{\alpha}^{+}\left(r_{1}\right) \Psi_{m}^{+}\left(r_{2}\right) \Psi_{s}^{+}\left(r_{3}\right) \Psi_{n}^{+}\left(r_{4}\right)\left(1-\alpha_{1} \alpha_{2}\right) / r_{12} .
\end{aligned}
$$


$\left\{\left[\left(\alpha_{3} \alpha_{4}-\left(\alpha_{3} n_{34}\right)\left(\alpha_{4} n_{34}\right)\right) / r_{34} \cdot \sin \left[\omega_{\alpha_{n}}\left(r_{12}+r_{34}\right)+\omega_{\alpha_{n}}\right.\right.\right.$.

$\left.\left.\cos \left[\omega_{\alpha_{n}}\left(r_{12}+r_{34}\right)\right]\left(1+\left(\alpha_{3} n_{34}\right)\left(\alpha_{4} n_{34}\right)\right)\right]\right\} \cdot$

$\cdot \Psi_{m}\left(r_{3}\right) \Psi_{\alpha}\left(r_{4}\right) \Psi_{n}\left(r_{2}\right) \Psi_{s}\left(r_{1}\right)$

Expression (31) can be represented in the form of sum of the following terms:

$\sum\left\langle\alpha m\left|W_{1}\right| n s\right\rangle\left\langle s n\left|W_{2}\right| m \alpha\right\rangle /\left(\omega_{m n} \pm \omega_{\alpha S}\right)$

With four different combinations of operators $\mathrm{W}_{1}$ and $\mathrm{W}_{2}$ (see [7-10]). In (31) it should be performed summation over the bound and upper continuum atomic states. To evaluate this sum, one can use the analytic relation between the atomic electron Fermi level and the core electron density $\rho_{c}(r)$, appropriate to the homogeneous nonrelativistic electron gas. Now the sum $\Sigma_{n>f, m<f}$ can be calculated analytically, its value becomes a functional of the core electron density. The resulting expression looks as the correction due to the additional nonlocal interaction of the active quasiparticle with the closed shells. Nevertheless, its calculation is reducible to the solving of the system of the ordinary differential equations (1-D procedure) [10]. The most important refinements can be introduced by accounting for the relativistic and the density gradient corrections to the Tomas- Fermi formula (see Refs. [2,3]). The same program is realized for other polarization diagrams. The minimization of the functional $\operatorname{Im} \delta E_{\text {ninv }}(\mathrm{b}+\mathrm{c})$ leads to the integro-differential equation for the $\rho_{\mathrm{c}}$ (the Dirac-like equations for electron density). In result we obtain the optimal one-quasiparticle representation. In concrete calculation it is sufficient to use the simplified procedure, which is reduced to functional minimization using the variation of the parameter $b$ in Eq.(9) $[2,10]$. Let us further to come back to the complex secular matrix $M$ in the form:

$$
M=M^{(0)}+M^{(1)}+M^{(2)}+M^{(3)} .
$$

Here $M^{(0)}$ is the contribution of the vacuum diagrams of all order of PT, and $M^{(1)}, M^{(2)}, M^{(3)}$ those of the one-, two- and three- quasiparticle diagrams respectively. $M^{(0)}$ is a real matrix, proportional to the unit matrix. It determines only the general level shift. It is usually assumed $M^{(0)}=0$. The diagonal matrix $M^{(1)}$ can be presented as a sum of the independent one-quasiparticle contributions. For simple systems (such as alkali atoms and ions) the one-quasiparticle energies can be taken from the experiment. Substituting these quantities into (33) one could have summarized all the contributions of the one -quasiparticle diagrams of all orders of the formally exact relativistic PT. The first two order corrections to $\operatorname{Re} M^{(2)}$ have been analyzed previously [2,5-9] using the Feynman diagrams technique. The contributions of the first-order diagrams have been completely calculated. In the second order, there are two kinds of diagrams: polarization and ladder ones. The polarization diagrams take into account the quasiparticle interaction through the polarizable core, and the ladder diagrams account for the immediate quasiparticle interaction. An effective form for the two-particle polarizable operator has been presented in Ref. [2]; it looks as:

$$
\begin{aligned}
& V_{p o l}^{d}\left(r_{1} r_{2}\right)=X\left\{\int \frac{d r^{\prime}\left(\rho_{c}^{(0)}\left(r^{\prime}\right)\right)^{1 / 3} \theta\left(r^{\prime}\right)}{\left|r_{1}-r^{\prime}\right| \cdot\left|r^{\prime}-r_{2}\right|}-\right. \\
& \left.-\int \frac{d r^{\prime}\left(\rho_{c}^{(0)}\left(r^{\prime}\right)\right)^{1 / 3} \theta\left(r^{\prime}\right)}{\left|r_{1}-r^{\prime}\right|} \int \frac{d r^{\prime \prime}\left(\rho_{c}^{(0)}\left(r^{\prime \prime}\right)\right)^{1 / 3} \theta\left(r^{\prime \prime}\right)}{\left|r^{\prime \prime}-r_{2}\right|} /\left\langle\left(\rho_{c}^{(0)}\right)^{1 / 3}\right\rangle\right\} \\
& \left\langle\left(\rho_{c}^{(0)}\right)^{1 / 3}\right\rangle=\int d r\left(\rho_{c}^{(0)}(r)\right)^{1 / 3} \theta(r) \\
& \theta(r)=\left\{1+\left[3 \pi^{2} \cdot \rho_{c}^{(0)}(r)\right]^{2 / 3} / c^{2}\right\}^{1 / 2},
\end{aligned}
$$

where $\rho_{c}^{0}$ is the core electron density (without account for the quasiparticle), $\mathrm{X}$ is numerical coefficient, $\mathrm{c}$ is the light velocity. The similar approximate potential representation has been received for the exchange polarization interaction of quasiparticles. Some of the ladder diagram contributions as well as some of the three-quasiparticle diagram contributions in all PT orders have the same angular symmetry as the two-quasiparticle diagram contributions of the first order. These contributions have been summarized by a modification of the central potential, which must now include the screening (anti-screening) of the core potential of each particle by the others (look Refs. [2,3,7-10,33-35]). The calculation of all the radial integrals reduces to solving a system of differential equations with known boundary conditions at $r=0$. Consider the master integral: 


$$
\begin{aligned}
& R_{\lambda}^{d}=\iiint d r_{1} d r_{2} d r_{3} r_{1}^{2} r_{2}^{2} r_{3}^{2} \rho_{1}\left(r_{1}\right) \tilde{U}_{\lambda}\left(r_{1} r_{3}\right) \\
& \rho_{c}^{1 / 3}\left(r_{3}\right) \tilde{U}_{\lambda}\left(r_{3} r_{2}\right) \rho_{2}\left(r_{2}\right)
\end{aligned}
$$

which enter the polarization contribution. This is the most complicated integral of a task. Let us note: $R^{d}=\lim _{r \rightarrow \infty} Y(r)$. According to [9], function $Y(r)$ can be found from solution of system of six differential equations with the boundary conditions:

$$
\begin{gathered}
Y_{1}^{\prime}=\left(\rho_{1} r^{2} Z_{\lambda}^{(1)}-(\lambda+1) Y_{1}\right) / r, \\
Y_{2}^{\prime}=\left(\rho_{2} r^{2} Z_{\lambda}^{(1)}{ }_{\lambda}-(\lambda+1) Y_{2}\right) / r, \\
Y_{3}^{\prime}=\left(\rho_{c}^{1 / 3} r^{2} Z_{\lambda}^{(1)} Z_{\lambda}^{(1)}-(2 \lambda+1) Y_{3}\right) / r, \\
Y_{4}^{\prime}=\left(\left(\rho_{2} r^{2} Y_{3}+\rho_{c}^{1 / 3} Y_{2} Z_{\lambda}^{(1)} Z_{\lambda}^{(2)}-(\lambda+1) Y_{4}\right) / r,\right. \\
Y_{5}^{\prime}=\left(\left(\rho_{1} r^{2} Y_{3}+\rho_{c}^{1 / 3} Y_{1} Z^{(1)}{ }_{\lambda} Z_{\lambda}^{(2)}-(\lambda+1) Y_{5}\right) / r,\right. \\
Y^{\prime}(r)=\left(\rho_{1} r^{2} Y_{4}+\rho_{2} r^{2} Y_{5}+\rho_{c}^{1 / 3} r^{2} Y_{1} Y_{2} Z_{\lambda}^{(2)}\right) Z_{\lambda}^{(2)} .
\end{gathered}
$$

A complete system of equations also includes equations for the modified Bessel functions $Z^{(i)}$ and for 1QP radial functions (see [2-8]).

\section{Some illustration results and conclusion}

In table 1 we present the experimental $[8,32-$ 25] an theoretical (our test calculation) results for hyperfine splitting energies for $1 \mathrm{~s}, 2 \mathrm{~s}$ levels of hydrogen atom. There is physically reasonable agreement between theory and experiment.

Table 1

\section{Experimental and theoretical data for HFS energies for 1s, 2s H-atom levels}

\begin{tabular}{|c|c|c|}
\hline Electron & Experiment & Theory \\
term & $\Delta v\left(\mathrm{~F}, \mathrm{~F}^{\prime}\right)$, & {$[13]$} \\
Quantum & $\mathrm{MHz}$, & $\Delta v\left(\mathrm{~F}, \mathrm{~F}^{\prime}\right)$, \\
numbers of & $\Delta \mathrm{E}\left(\mathrm{F}, \mathrm{F}^{\prime}\right)$, & $\mathrm{MHz}$ \\
total moment & $10^{-3} \mathrm{~cm}^{-1}$ & $\Delta \mathrm{E}\left(\mathrm{F}, \mathrm{F}^{\prime}\right)$, \\
& & $10^{-3} \mathrm{~cm}^{-1}$ \\
\hline $1 \mathrm{~s}^{2} \mathrm{~S}_{1 / 2}(1,0)$ & 1420,406 & 1419,685 \\
& 47,379 & 47,355 \\
\hline $2 \mathrm{~s}^{2} \mathrm{~S}_{1 / 2}(1,0)$ & 177,557 & 177,480 \\
& 5,923 & 5,920 \\
\hline
\end{tabular}

In table 2 there are listed the results of calculation for the hyperfine structure parameters (plus derivatives of the energy contribution on nuclear radius) for the superheavy $\mathrm{H}$-like ion with nuclear charge $Z=170$. We have used the denotations $[7,8]$ :

$$
A=10^{8} \mathrm{~A} / \mathrm{Z}^{3} \mathrm{~g}_{l},(\mathrm{eV})
$$

$D A=\left(10^{-2} / Z^{4} g_{I}\right)(\partial A / \partial R),(e V / c m)$;

$B=\left(10^{7} B I(2 I-1)\right) / Z^{3} Q$, (eV/Barn);

$D B=\left[\left(10^{-3} I(2 I-1)\right) / Z^{4} Q\right](\partial B / \partial R),($ eV/Barn cm $) ;$

$$
U=-\left(10^{4} / Z^{4}\right)<U(r, R)>,(e V) ;
$$

$D U=\left(10^{-1} / Z^{5}\right)(2<U(r, R)>/ \partial R),(\mathrm{eV} / \mathrm{cm}) ;$

$$
D V=\left[10^{-8} / Z^{3}\right](2<V>/ \partial R),(\mathrm{eV} / \mathrm{cm}) ;
$$

Table 2

\section{Parameters of one-electron states for $\mathrm{H}$-like} ion with $Z=170$ (data from $[8,35]$ )

\begin{tabular}{|c|c|c|c|c|}
\hline & $1 \mathrm{~s}_{1 / 2}$ & $2 \mathrm{~s}_{1 / 2}$ & $2 \mathrm{p}_{1 / 2}$ & $2 \mathrm{p}_{3 / 2}$ \\
\hline$A$ & 4337 & 831 & 3867 & 1,59 \\
\hline$D A$ & 1039 & 228 & 941 & 0,0001 \\
\hline$B$ & 9091 & 1897 & 8067 & 0,07 \\
\hline$D B$ & 7245 & 1557 & 6405 & 0,0008 \\
\hline$D V$ & 1255 & 273 & 1108 & 0,0011 \\
\hline$U$ & 1453 & 282 & 1301 & 1,31 \\
\hline$D U$ & 2343 & 503 & 2071 & 0,0015 \\
\hline & $1 \mathrm{~s}_{1 / 2}$ & $3 \mathrm{~s}_{1 / 2}$ & $3 \mathrm{p}_{1 / 2}$ & $3 \mathrm{p}_{3 / 2}$ \\
\hline$A$ & 4337 & 207 & 322 & 0,615 \\
\hline$D A$ & 1039 & 56,8 & 84,0 & 0,0001 \\
\hline$B$ & 9091 & 475 & 707 & 0,04 \\
\hline$D B$ & 7245 & 395 & 574 & 0,0003 \\
\hline$D V$ & 1255 & 67,7 & 98,3 & 0,0005 \\
\hline$U$ & 1453 & 69,3 & 109 & 0,62 \\
\hline$D U$ & 2343 & 127 & 185 & 0,0007 \\
\hline
\end{tabular}

In table 3 there are listed the nuclear corrections into energy of the low transitions for Li-like ions. 
Table 3

Nuclear finite size corrections into energy $\left(\mathrm{cm}^{-1}\right)$ for Li-like ions and values of the effective radius of nucleus $\left(10^{-13} \mathrm{~cm}\right)$

\begin{tabular}{|c|c|c|c|}
\hline $\mathrm{Z}$ & $2 \mathrm{~s}_{1 / 2}-2 \mathrm{p}_{1 / 2}$ & $2 \mathrm{~s}_{1 / 2}-2 \mathrm{p}_{3 / 2}$ & $\mathrm{R}$ \\
\hline 20 & $-15,1$ & $-15,5$ & 3,26 \\
\hline 41 & $-659,0$ & $-670,0$ & 4,14 \\
\hline 69 & $-20690,0$ & $-21712,0$ & 4,93 \\
\hline 79 & $-62315,0$ & $-66931,0$ & 5,15 \\
\hline 92 & $-267325,0$ & $-288312,0$ & 5,42 \\
\hline
\end{tabular}

The calculation showed also that a variation of the nuclear radius on several persents could lead to changing the transition energies on dozens of thousands $10^{3} \mathrm{~cm}^{-1}$. In $[8,32,35]$ there are listed the results of calculating the constants of the hyperfine interaction: the electric quadruple constant $B$, the magnetic dipole constant $A$ with inclusion of nuclear finiteness and the UehlingSerber potential for some Li-like ions. In table 4 data on the HFS constants for lowest excited states of Li-like ions are listed. Similar data for other states were listed earlier (see ref. $[8,32,34]$ ), but there another model for a charge distribution in a nucleus and method of treating the QED corrections were used.

Table 4.

\section{Constants of the hyperfine electron-nuclear}

interaction: $\mathbf{A}=\mathbf{Z}^{3} \mathbf{g}_{\mathbf{I}} \bar{A} \mathbf{c m}_{1}^{-1}, \quad \mathbf{B}=\frac{Z^{3} Q}{I(2 I-1)} \bar{B} \mathbf{c m}^{-}$

\begin{tabular}{|c|l|c|c|c|}
\hline$n l j$ & $Z$ & 20 & 79 & 92 \\
\hline $2 s$ & $\bar{A}$ & $93-03$ & $215-02$ & $\begin{array}{c}314 \\
-02\end{array}$ \\
\hline $3 s$ & $\bar{A}$ & $26-03$ & $63-03$ & $90-03$ \\
\hline $2 p_{1 / 2}$ & $\bar{A}$ & $25-03$ & $71-03$ & $\begin{array}{c}105 \\
-02\end{array}$ \\
\hline $3 p_{1 / 2}$ & $\bar{A}$ & $81-04$ & $20-03$ & $31-03$ \\
\hline
\end{tabular}

\begin{tabular}{|l|l|c|c|c|}
\hline $2 p_{3 / 2}$ & $\bar{A}$ & $50-04$ & $71-04$ & $72-04$ \\
\hline & $\bar{B}$ & $9-04$ & $15-04$ & $17-04$ \\
\hline $3 p_{3 / 2}$ & $\bar{A}$ & $13-04$ & $21-04$ & $22-04$ \\
\hline & $\bar{B}$ & $31-05$ & $55-05$ & $62-05$ \\
\hline $3 d_{3 / 2}$ & $\bar{A}$ & $88-05$ & $11-04$ & $12-04$ \\
\hline & $\bar{B}$ & $51-06$ & $10-05$ & $11-05$ \\
\hline $3 d_{5 / 2}$ & $\bar{A}$ & $36-05$ & $50-05$ & $52-05$ \\
\hline & $\bar{B}$ & $21-06$ & $39-06$ & $40-06$ \\
\hline
\end{tabular}

\section{References}

1. Grant I.P., Relativistic Quantum Theory of Atoms and Molecules. - Oxford, 2008. $-650 \mathrm{p}$.

2. Glushkov A.V., Relativistic Quantum Theory. Quantum, mechanics of Atomic Systems. - Odessa: Astroprint, 2008. - 700 p.

3. Glushkov A.V., Relativistic and correlation effects in spectra of atomic systems.-Odessa: Astroprint. - 2006. $400 \mathrm{p}$.

4. Glushkov A.V., Atom in electromagnetic field. - Kiev: KNT, 2005. - 450P.

5. Ivanov L.N.,Ivanova E.P., Extrapolation of atomic ion energies by model potential method: Na-like spectra/ // Atom. Data Nucl. Data Tab. - 1999. - Vol.24. - P. 95-121.

6. Ivanov L.N., Letokhov V.S., Autoionization states of multielectron atoms// Com. Of Modern Phys. D. Atom. and Mol.Phys. -1995. -Vol. 4. - P. 169-184.

7. Ivanova E.P., Ivanov L.N., Glushkov A.V., Kramida A.E. High order corrections in the relativistic perturbation theory with the model zeroth approximation, $\mathrm{Mg}$-like and Ne-like ions // Phys.Scripta -1985. - Vol. 32, № 4. - P. 513-522. 
8. Ivanova E.P., Ivanov L.N., Aglitsky E.V., Modern Trends in Spectroscopy of multi-charged Ions// Phys.Rep. - 1998. Vol. 166, № 6. - P. 315-390.

9. Glushkov A.V., Ivanov L.N., Ivanova E.P., Radiation decay of atomic states. Generalized energy approach// Autoionization Phenomena in Atoms.- M.: Moscow State Univ. - 1986. - P.58-160.

10. Glushkov A.V., Ivanov L.N. Radiation decay of atomic states: atomic residue polarization and gauge non-invariant contributions//Phys.Lett.A. - 1992. - Vol. 170. - P. 33-36.

11. Ivanov L.N., Ivanova E.P., Knight L., Energy approach to consistent QED theory for calculation of electron-collision strengths// Phys. Rev.A. - 1993. Vol. 48. - P. 4365-4374.

12. Glushkov A.V., Khetselius O.Yu., Loboda A.V., Svinarenko A.A., QED approach to atoms in a laser field: Multiphoton resonances and above threshold ionization//Frontiers in Quantum Systems in Chemistry and Physics, Ser.: Progress in Theoretical Chemistry and Physics; Eds. S.Wilson, P.J.Grout, J. Maruani, G. Delgado-Barrio, P. Piecuch (Springer), 2008. - Vol.18.P. 543-560.

13. Glushkov A.V., Khetselius O.Y., Malinovskaya S.V., New laser-electron nuclear effects in the nuclear $\gamma$ transition spectra in atomic and molecular systems// Frontiers in Quantum Systems in Chemistry and Physics. Series: Progress in Theoretical Chemistry and Physics Eds. S.Wilson, P.J.Grout, J. Maruani, G. Delgado-Barrio, P. Piecuch (Springer). - 2008. - Vol. 18. - 525 p.

14. Glushkov A.V., Khetselius O.Yu., Svinarenko A.A., Prepelitsa G.P., Energy approach to atoms in a laser field and quantum dynamics with laser pulses of different shape//In: Coherence and Ultrashort Pulse Laser Emission, Ed. by Dr. F. Duarte (InTech). - 2010. - P. 159-186.

15. Glushkov A.V., Khetselius O., Svinarenko A, Relativistic theory of cooperative muon- $\gamma$ gamma-nuclear processes:
Negative muon capture and metastable nucleus discharge// Advances in the Theory of Quantum Systems in Chemistry and Physics. Ser.: Progress in Theor. Chem. and Phys., Eds. P.Hoggan, E.Brandas, J.Maruani, G. DelgadoBarrio, P.Piecuch (Springer). - 2012. Vol. 22. $-51 \mathrm{p}$.

16. Glushkov A.V., Rusov V.D., Ambrosov S.V., Loboda A.,Resonance states of compound super-heavy nucleus and EPPP in heavy nucleus collisions//New projects and new lines of research in nuclear physics. Eds. G.Fazio, F.Hanappe, Singapore : World Scientific. - 2003. P. 126-132.

17. Glushkov A.V., Khetselius O.Yu., Prepelitsa G., Svinarenko A.A., Geometry of Chaos: Theoretical basis's of a consistent combined approach to treating chaotic dynamical systems and their parameters determination //Proc. of International Geometry Center". - 2013. - Vol. 6, N 1. - P. 43-48.

18. Malinovskaya S.V., Glushkov A.V., Dubrovskaya Yu.V., Vitavetskaya L.A., Quantum calculation of cooperative muon-nuclear processes: discharge of metastable nuclei during negative muon capture// Recent Advances in the Theory of Chemical and Physical Systems (Springer). - 2006. - Vol. 15. - P. 301-307.

19. Malinovskaya S.V., Glushkov A.V., Khetselius O.Yu., Lopatkin Yu., Loboda A.V., Svinarenko A., Nikola L., Perelygina T., Generalized energy approach to calculating electron collision cross-sections for multicharged ions in a plasma: Debye shielding model// Int. Journ. Quant. Chem. - 2011. - Vol. 111, N 2. - P. 288-296.

20. Malinovskaya S.V., Glushkov A.V., Khetselius O.Yu., Svinarenko A.A., Mischenko E.V., Florko T.A., Optimized perturbation theory scheme for calculating the interatomic potentials and hyperfine lines shift for heavy atoms in the buffer inert gas//Int. Journ. Quant.Chem. - 2009. - Vol. 109, N 14. - P. 3325-3329. 
21. Glushkov A.V., Khetselius O.Y., Malinovskaya S.V., Spectroscopy of cooperative laser-electron nuclear effects in multiatomic molecules// Molec. Phys. (UK). - 2008. - Vol. 106. - N 9-10. P. 1257-1260.

22. Glushkov A.V., Khetselius O.Yu., Svinarenko A.A., Prepelitsa G.P., Mischenko E.V., The Green's functions and density functional approach to vibrational structure in the photoelectron spectra for molecules// AIP Conf. Proceedings. - 2010. - Vol.1290. - P. 263-268.

23. Glushkov A.V, Malinovskaya S.,Co-operative laser nuclear processes: border lines effects//In: New projects and new lines of research in nuclear physics. Eds. G.Fazio and F.Hanappe, Singapore : World Scientific. -2003 . - P. 242-250.

24. Glushkov A.V., Effective quasi-particle valence hamiltonian of molecules in the comprehensive semi-empirical theory// Sov. Journ. Struct. Chem. - 1998. Vol. 29, N 4. - P. 3-9.

25. Glushkov A.V., Loboda A.V., Gurnitskaya E., Svinarenko A., QED theory of radiation emission and absorption lines for atoms in a strong laser field//Phys. Scripta. - 2009. - T. 135. - P. 014022.

26. Glushkov A.V., Malinovskaya S.V., Prepelitsa G.P., Ignatenko V.M., Manifestation of the new laser-electron nuclear spectral effects in thermalized plasma: QED theory of cooperative laser-electronnuclear processes//J. Phys.:Conf.Ser. 2005. - Vol. 11. - P. 199-206.

27. Glushkov A.V., Malinovskaya S.V., Ambrosov S., Shpinareva I.M., Troitskaya O.V., Resonances in quantum systems in strong external fields consistent quantum approach// J. of Techn.Phys.-1997. - Vol. 38, Iss.2. - P. 215-218.

28. Glushkov A.V., Malinovskaya S.V., Loboda A., Shpinareva I.M.,Gurnitskaya E., Korchevsky D., Diagnostics of the collisionally pumped plasma and search of the optimal plasma parameters of x-ray lasing: Calculation of electron-collision strengths and rate coefficients for Ne-like plasma// J. Phys.: Conf.Ser. - 2005. Vol.11. - P. 188-198.
29. Glushkov A.V., Lovett L., Khetselius O.Yu., Gurnitskaya E.P., Dubrovskaya Yu.V., Loboda A.V., Generalized multiconfiguration model of decay of multipole giant resonances applied to analysis of reaction $(\mu-n)$ on the nucleus ${ }^{40} \mathrm{Ca} / /$ Internat. Journ. Modern Physics A. - 2009. Vol. 24, N. 2-3. - P. 611-615.

30. Glushkov A.V., Malinovskaya S.V., Sukharev D.E., Khetselius O.Yu., Loboda A.V., Lovett L., Green's function method in quantum chemistry: New numerical algorithm for the Dirac equation with complex energy and Fermi-model nuclear potential//Int.Journ. Quant. Chem. - 2009. - Vol. 109. - N 8. P. 1717-1727.

31. Glushkov A.V., Kondratenko P.A., Lepikh Ya., Fedchuk A.P., Svinarenko A.A., Lovett L., Electrodynamical and quantum - chemical approaches to modelling the electrochemical and catalytic processes on metals, metal alloys and semiconductors//Int. Journ. Quantum Chem. - 2009. - Vol. 109, N 14. P. 3473-3481.

32. Khetselius O.Yu., Relativistic calculating the hyperfine structure parameters for heavy-elements and laser detecting the isotopes and nuclear reaction products//Phys.Scripta. - 2009. - T. 135. P. 014023.

33. Glushkov A.V., Khetselius O.Yu., Lovett L., Electron- $\beta$-Nuclear Spectroscopy of Atoms and Molecules and Chemical Bond Effect on the $\beta$-Decay parameters// Advances in the Theory of Atomic and Molecular Systems Dynamics, Spectroscopy, Clusters, and Nanostructures. Series: Progress in Theor. Chem. and Phys., Eds. Piecuch P., Maruani J., Delgado-Barrio G., Wilson S. (Springer). - 2009. - Vol. 20. P. 125-152.

34. Glushkov A.V., Svinarenko A.A., Khetselius O.Yu., Buyadzhi V.V., Florko T.A., Shakhman A.N., Relativistic Quantum Chemistry: An Advanced approach to the construction of the Green function of the Dirac equation with com- 
plex energy and mean-field nuclear potential// Frontiers in Quantum Methods and Applications in Chem. and Physics. Ser.: Progress in Theor. Chemistry and Phys., Eds. M. Nascimento, J.Maruani, E.Brändas, G. Delgado-Barrio (Springer). - 2015. - Vol. 29. - P. 197-217.

35. Khetselius O.Yu., Optimized perturbation theory to calculating the hyperfine line shift and broadening for heavy atoms in the buffer gas// Frontiers in Quantum Methods and Applications in Chemistry and Physics. Ser.: Progress in Theor. Chem. and Phys., Eds. M.Nascimento, J.Maruani, E.Brändas, G.Delgado-Barrio (Springer), - 2015. Vol. 29. - P. 55-76.

36. Glushkov A.V., Malinovskaya S.V., New approach to the formation of model potential for valence-electrons// Zhurn.Fizich.Khimii.-1988.-Vol.62(1).P.100-104.

37. Glushkov A.V.,Lepikh Ya.I.,Khetselius O.Yu., Fedchuk A.P., Ambrosov S.V, Ignatenko A.V., Wannier-mott excitons and atoms in a DC elecric field: photoionization, Stark effect, resonances in the ionization continuum// Sensor Electr. and Microsyst. Techn.-2008.N4.-P.5-11.

38. Khetselius O.Yu., Relativistic energy approach to cooperative electron$\gamma$-nuclear processes: NEET Effect// Quantum Systems in Chemistry and Physics: Progress in Methods and Applications. Ser.: Progress in Theor. Chem. and Phys., Eds. K.Nishikawa, J. Maruani, E.Brandas, G. Delgado-Barrio, P.Piecuch (Springer).-2012-Vol.26.P.217.

39. Buyadzhi V.V., Glushkov A.V., Lovett L., Spectroscopy of atoms and nuclei in a strong laser field: AC Stark effect and multiphoton resonances// Photoelectronics.-2014.-Vol.23.-P. 3843.

40. Ternovsky V.B., Glushkov A.V., Zaichko P., Khetselius O.Yu., Florko T.A., New relativistic model potential approach to sensing radiative transitions probabili- ties in spectra of heavy Rydberg atomic systems/ // Sensor Electr. and Microsyst. Techn.-2015.-Vol.12,N4.-P.19-26.

41. Buyadzhi V.V., Glushkov A.V., Mansarliysky V.F., Ignatenko A.V., Svinarenko A.A., Spectroscopy of atoms in a strong laser field: New method to sensing AC Stark effect, multiphoton resonances parameters and ionization crosssections//Sensor Electr. and Microsyst. Techn.-2015.-Vol.12,N4.-P.27-36.

42. Glushkov A.V., Mansarliysky V.F., Khetselius O.Yu., Ignatenko A.V., Smirnov A., Prepelitsa G.P., Collisional shift of hyperfine line for thallium in an atmosphere of the buffer inert gas // Journal of Physics: C Series (IOP, London, UK).-2017.-Vol.810.-P. 012034.

43. Buyadzhi V.V., Zaichko P.A., Gurskaya M., Kuznetsova A.A., Ponomarenko E.L., Ternovsky E.,Relativistic theory of excitation and ionization of Rydberg atoms in a Black-body radiation field//J. Phys.: Conf. Series.-2017.-Vol.810.-P. 012047.

44. Glushkov A.V., Khetselius O.Y., Brusentseva S.V., Zaichko P.A., Ternovsky V.B., Studying interaction dynamics of chaotic systems within a non-linear prediction method: application to neurophysiology// Advances in Neural Networks, Fuzzy Systems and Artificial Intelligence, Series: Recent Advances in Computer Engineering, Ed. J.Balicki.-2014.-Vol.21.-P.69-75.

45. Glushkov A.V., Svinarenko A.A., Buyadzhi V.V., Zaichko P., Ternovsky V., Chaos-geometric attractor and quantum neural networks approach to simulation chaotic evolutionary dynamics during perception process// Advances in Neural Networks, Fuzzy Systems and Artificial Intelligence, Series: Recent Advances in Computer Engineering, Ed. J.Balicki.-2014.-Vo1.21.-P.143-150.

46. Glushkov A.V., Spectroscopy of atom and nucleus in a strong laser field: Stark effect and multiphoton Resonances// J.Phys.: Conf. Series (IOP).-2014.Vol.548.-P.012020. 
47. Glushkov A.V., Kondratenko P.A., Buyadzhi V.V., Kvasikova A.S., Shakhman A.S., Sakun T.N., Spectroscopy of cooperative laser electron- $\gamma$-nuclear processes in polyatomic molecules// J. Phys.: Conf. Ser.-2014.-Vol.548.-P.012025

48. Glushkov A.V., Khetselius O.Yu., Lopatkin Y., Florko T.A., Kovalenko O., Mansarliysky V., Collisional shift of hyperfine line for rubidium in an atmosphere of the buffer inert gas $/ / \mathrm{J}$. Phys.:Conf.Series.-2014.-Vol.548.P.012026

49. Svinarenko A.A., Study of spectra for lanthanides atoms with relativistic many- body perturbation theory: Rydberg resonances// J. Phys.: Conf. Ser.-2014.-Vol.548.-P.012039.

50. Svinarenko A.A., Ignatenko A.V., Ternovsky V.B., Nikola V.V., Seredenko S.S., Tkach T.B., Advanced relativistic model potential approach to calculation of radiation transition parameters in spectra of multicharged ions// J. Phys.: Conf. Ser. -2014.-Vol.548.-P. 012047.

51. Svinarenko A.A., Khetselius O.Yu., Buyadzhi V.V., Florko T.A., Zaichko P.A., Ponomarenko E.L., Spectroscopy of Rydberg atoms in a Black-body radiation field: Relativistic theory of excitation and ionization// J. Phys.: Conf. Ser.-2014.-Vol.548.-P. 012048.

52. Glushkov A.V., Khetselius O.Yu., Bunuakova Yu.Ya., Buyadzhi V.V, Brusentseva S.V., Zaichko P.A., Sensing interaction dynamics of chaotic systems within a chaos theory and microsystem technology Geomath with application to neurophysiological systems// Sensor Electr. and Microsyst.Techn.-2014.-Vol. 11,N3.-P.62-69.

53. Prepelitsa G.P., Glushkov A.V., Lepikh Ya.I., Buyadzhi V.V., Ternovsky V.B., Zaichko P.A., Chaotic dynamics of nonlinear processes in atomic and molecular systems in electromagnetic field and semiconductor and fiber laser devices: new approaches, uniformity and charm of chaos// Sensor Electr. and Microsyst. Techn.-2014.-Vol.11,N4.-P.43-57.
54. Khetselius O., Hyperfine structure of atomic spectra.-Odessa: Astroprint, 2008.-210P.

55. Khetselius O.Yu., Hyperfine structure of radium// Photoelectronics.-2005.-N14.P.83-85.

56. Khetselius O., Spectroscopy of cooperative electron-gamma-nuclear processes in heavy atoms: NEET effect// J. Phys.: Conf. Ser.-2012.- Vol.397.-P.012012

57. Khetselius O.Yu., Florko T.A., Svinarenko A.A., Tkach T.B., Radiative and collisional spectroscopy of hyperfine lines of the Li-like heavy ions and $\mathrm{Tl}$ atom in an atmosphere of inert gas//Phys.Scripta.-2013.-Vol.T153P.014037.

58. Khetselius O.Yu., Turin A.V., Sukharev D.E., Florko T.A., Estimating of Xray spectra for kaonic atoms as tool for sensing the nuclear structure// Sensor Electr. and Microsyst. Techn.-2009.N1.-P.30-35.

59. Khetselius O.Yu., On possibility of sensing nuclei of the rare isotopes by means of laser spectroscopy of hyperfine structure//Sensor Electr. and Microsyst.Techn.-2008.-Vol.3.-P.28-33.

60. Glushkov A.V., Malinovskaya S.V, Gurnitskaya E.P., Khetselius O.Yu.,Dubrovskaya Yu.V., Consistent quantum theory of the recoil induced excitation and ionization in atoms during capture of neutron// Journal of Physics: Conf. Series (IOP).-2006.- Vol.35.P.425-430.

61. Glushkov A.V., Khetselius O.Y., Brusentseva S.V., Zaichko P.A., Ternovsky V.B., Studying interaction dynamics of chaotic systems within a non-linear prediction method: application to neurophysiology// Advances in Neural Networks, Fuzzy Systems and Artificial Intelligence, Ser: Recent Adv. in Computer Engineering, Ed. J.Balicki.-2014.Vol.21.-P.69-75.

62. Khetselius O.Yu., Quantum Geometry: New approach to quantization of the quasistationary states of Dirac equation for super heavy ion and calculating hy- 
per fine structure parameters// Proc. Int. Geometry Center.-2012.-Vol.5,№ 3-4.P.39-45.

63. Glushkov A.V., Khetselius O.Yu., Svinarenko A.A., Theoretical spectroscopy of autoionization resonances in spectra of lanthanide atoms// Physica Scripta.2013.-Vol.T153.-P.014029.

64. Glushkov A.V., Khetselius O.Yu., Gurnitskaya E.P., Loboda A.V., Sukharev D.E., Relativistic quantum chemistry of heavy ions and hadronic atomic systems: spectra and energy shifts//Theory and Applications of Computational Chemistry. AIP Conference Proceedings.2009.-Vol. 1102.-P. 168-171.

65. Khetselius O.Yu., Relativistic calculating the spectral lines hyperfine structure parameters for heavy ions//Spectral Line Shapes, AIP Conf. Proceedings.2008.-Vol. 1058.-P. 363-365.

66. Khetselius O.Yu., Glushkov A.V., Gurnitskaya E.P., Loboda A.V., Mischenko E.V., Florko T.A., Sukharev D.E., Collisional Shift of the Tl hyperfine lines in atmosphere of inert gases// Spectral Line Shapes, AIP Conf. Proceedings.2008.-Vol. 1058.-P. 231-233.

67. Khetselius O.Yu., Hyperfine structure of energy levels for isotopes $73 \mathrm{Ge}$, 75As, 201Hg// Photoelectronics.-2007.N 16.-P. 129-132.

68. Khetselius O.Y., Gurnitskaya E.P., Sensing the electric and magnetic moments of a nucleus in the N-like ion of $\mathrm{Bi} / /$ Sensor Electr. and Microsyst. Techn.-2006.-N 3.-P. 35-39.

69. Khetselius O.Y., Gurnitskaya E.P., Sensing the hyperfine structure and nuclear quadrupole moment for radium// Sensor Electr. and Microsyst. Techn.-2006.N 2.-P. 25-29.

70. Florko T.A., Loboda A.V., Svinarenko A.A., Sensing forbidden transitions in spectra of some heavy atoms and multicharged ions: New theoretical scheme// Sensor Electr. and Microsyst. Techn.-2009.-N 3.-P. 10-15.

71. Sukharev D.E., Khetselius O.Yu., Dubrovskaya Yu.V., Sensing strong interac- tion effects in spectroscopy of hadronic atoms// Sensor Electr. and Microsyst. Techn.-2009.-N 3.-P. 16-21.

72. Glushkov A.V., Khetselius O.Yu., Kuzakon V., Prepelitsa G.P., Solyanikova E.P., Svinarenko A., Modeling of interaction of the non-linear vibrational systems on the basis of temporal series analyses (application to semiconductor quantum generators)// Dynamical Systems-Theory and Applications.-2011.BIF110.

73. Svinarenko A.A., Nikola L. V., Prepelitsa G., Tkach T.B, Mischenko E.V., Auger (autoionization) decay of excited states in spectra of multicharged ions: Relativistic theory//AIP Conf.Proceedings. 2010. - Vol.1290, N1. - P. 94-98.

74. Glushkov A.V., Khetselius O.Yu., Loboda A.V., Ignatenko A., Svinarenko A., Korchevsky D., Lovett L., QED approach to modeling spectra of the multicharged ions in a plasma: Oscillator and electron-ion collision strengths// Spectral Line Shapes. AIP Conference Proceedings.-2008.-Vol.1058.P.175-177

75. Glushkov A.V., Svinarenko A.A., Nuclear quantum optics: Energy approach to multi-photon resonances in nuclei // Sensor Electr. and Microsyst. Techn.-2010.-N2.-P.5-10.

76. Glushkov A.V., Energy approach to resonance states of compound super-heavy nucleus and EPPP in heavy nuclei collisions// Low Energy Antiproton Phys. AIP Conference Proceedings.-2005.Vol.796.-P.206-210.

77. Malinovskaya S.V., S.V., Dubrovskaya Yu., Vitavetskaya L., Advanced quantum mechanical calculation of the beta decay probabilities// Low Energy Antiproton Phys. AIP Conference Proceedings.-2005.-Vol.796.P.201-205.

78. Glushkov A.V., Ambrosov S.V., Loboda A., Gurnitskaya E.P., Prepelitsa G.P., Consistent QED approach to calculation of electron-collision excitation crosssections and strengths: Ne-like ions// 
Int. Journ.Quant.Chem.-2005.-Vol.104, N4 .-P. 562-569.

79. Glushkov A.V., Ambrosov S.V., Ignatenko A.V., Korchevsky D.A., DC Strong Field Stark effect for non-hydrogenic atoms: Consistent quantum mechanical approach// Int.Journ. Quant. Chem.-2004.-Vol.99,N6.-P.936-939.

80. Glushkov A.V, Malinovskaya S.V, Chernyakova Y.G., Svinarenko A.A., Cooperative laser-electron-nuclear processes: QED calculation of electron satellites spectra for multi-charged ion in laser field// Int. Journ. Quant. Chem.2004. - Vol. 99, N 6. - P. 889-893.

81. Glushkov A.V, Khetselius O.Yu, Malinovskaya S.V, Optics and spectroscopy of cooperative laser-electron nuclear processes in atomic and molecular systems - new trend in quantum optics// Europ. Phys. Journ. ST. - 2008. - Vol. 160, N 1. - P. 195-204.

82. Glushkov A.V., Dan'kov S.V., Prepelitsa G., Polischuk V.N., Efimov A., Qed theory of nonlinear interaction of the complex atomic systems with laser field multi-photon resonances// Journal of Tech. Phys. - 1997. - Vol. 38 (2). P. 219-222

83. Glushkov A.V., Operator Perturbation Theory for Atomic Systems in a Strong DC Electric Field//Advances in Quantum Methods and Applications in Chemistry, Physics, and Biology. Series: Frontiers in Theoretical Physics and Chemistry, Eds. M.Hotokka, J.Maruani, E. Brändas, G.DelgadoBarrio (Springer). - 2013. -Vol. 27.P. 161-177.

84. Glushkov A.V., Ambrosov S.V., Loboda A.V., Gurnitskaya E.P., Khetselius O.Yu., QED calculation of heavy multicharged ions with account for the correlation, radiative and nuclear effects// Recent Advances in Theor. Phys. and Chem. Systems.-2006.-Vol.15.P.285-300.

85. Glushkov A.V., Calculation of parameters of the interaction potential between excited alkali atoms and mercury at- oms-the Cs-, Fr-Hg interaction// Optika i Spektr.-1994.-Vol.77 (1).-P.5-10.

86. Glushkov A.V.,Khetselius O.Yu., Gurnitskaya E.P., Korchevsky D.A., Loboda A.V., Prepelitsa G.P., Sensing the electron-collision excitation cross-sections for $\mathrm{Ne}$-like ions of $\mathrm{Fe}$ in a plasma in the Debye shileding approximation// Sensor Electr. and Microsyst. Techn.-2007.N2.-P.9-13

87. Glushkov A.V., Khetselius O.Yu., Gurnitskaya E.P., Florko T.A., Sensing of nuclei available in little quantities by means of laser spectroscopy of hyperfine structure for isotopes: new theoretical scheme (U ,Hg) // Sensor Electr. and Microsyst. Techn.-2007.-N3.-P.8-12.

88. Glushkov A.V., Bunyakova Yu.Ya., Zaichko P., Geometry of Chaos: Consistent combined approach to treating chaotic dynamics atmospheric pollutants and its forecasting// Proc. International Geometry Center".-2013.-Vol.6, N3.P.6-14.

89. Glushkov A.V., Khetselius O.Yu., Prepelitsa G.P., Svinarenko A.A., Geometry of Chaos I: Theoretical basis's of a consistent combined approach//Proc. Int. Geometry Center.-2013.-Vol.6,N1.P.67-79.

90. Chernyakova Yu.G., Dubrovskaya Yu.V., Florko T.A., Romanova A.V., Vitavetskaya L., An advanced approach to quantization of the quasi stationary states of Dirac-Slater equation// Proc. Int. Geometry Center.-2013.-Vol.6,N2.P.29-34.

91. Glushkov A.V., Khetselius O., Dubrovskaya Yu.V., Loboda A.V., Sensing the capture of negative muon by atoms: Energy approach// Sensor Electr. and Microsyst. Techn.-2006.-N4.-P.31-35.

92. Serbov N.G., Glushkov A.V., Bunyakova Yu.Ya., Prepelitsa G.P., Svinarenko A.A., Sensing the kinetical features of energy exchange in mixture $\mathrm{CO}_{2}-\mathrm{N}_{2}-\mathrm{H}_{2} \mathrm{O}$ of atmospheric gases under interacting with laser radiation// Sensor Electr. and Microsyst. Techn.-2006.-N4.-P.20-22.

93. Glushkov A.V., Khetselius O.Y., Bun- 
yakova Yu.Ya., Prepelitsa G.P., Solyanikova E.P., Serga E., Non-linear prediction method in short-range forecast of atmospheric pollutants: low-dimensional chaos// Dynamical Systems Theory and Applications (Lodz).-2011.P.39-44 (LIF111).

94. Khetselius O.Yu., Forecasting evolutionary dynamics of chaotic systems using advanced non-linear prediction method// Dynamical Systems - Theory and Applications, Eds. J. Awrejcewicz, M. Kazmierczak, P. Olejnik, J, Mrozowski.-2013.-Vol.1.-P.145-152.

95. Glushkov A.V., Kuzakon V.M., Ternovsky V.B., Buyadzhi V.V., Dynamics of laser systems with absorbing cell and backward-wave tubes with elements of a chaos// Dynamical Systems - Theory and Applications, Eds. J. Awrejcewicz, M. Kazmierczak, P. Olejnik, J, Mrozowski.-2013.-Vol.T1.-P.461-466.

96. Bunyakova Yu.Ya., Khetselius O.Yu., Non-linear prediction statistical method in forecast of atmospheric pollutants// Proc. of 8th International Carbon Dioxide Conference.-2009.-P.T2-098.

97. Glushkov A.V., Khetselius O., Svin- arenko A.A., Lovett L., Energy approach to nuclei and atoms in a strong laser field: Stark effect and multi-photon resonances // Quantum Theory: Reconsideration of Foundations. AIP Conference Proceedings.-2010.-Vol.1232.P.228-234.

98. Svinarenko A.A., Glushkov A.V., Loboda A.V., Sukharev D.E., Dubrovskaya Yu.V., Mudraya N.V., Serga I.N., Green's function of the Dirac equation with complex energy and non-singular central nuclear potential//Quantum Theory: Reconsideration of Foundations. AIP Conf. Proceedings.-2010.Vol.1232.-P.259-266.

99. Khetselius O. Yu., Florko T. A., Nikola L., Svinarenko A., Serga I., Tkach T., Mischenko E., Hyperfine structure, scalar-pseudoscalar interaction and parity non-conservation effect in some heavy atoms and ions// Quantum Theory: Reconsideration of Foundations. AIP Conference Proceedings.-2010.-Vol.1232.P.243-250.

This article has been received in May 2017

UDC 539.182

\title{
A. V. Glushkov, V. B. Ternovsky, A. V. Smirnov, A. A. Svinarenko
}

\section{GAUGE-INVARIANT RELATIVISTIC PERTURBATION THEORY APPROACH TO DETERMINATION OF ENERGY and SPECTRAL CHARACTERISTICS FOR HEAVY AND SUPERHEAVY ATOMS AND IONS: REVIEW}

\begin{abstract}
Summary
We reviewed an effective consistent ab initio approach to relativistic calculation of the spectra for multi-electron heavy and superheavy ions with an account of relativistic, correlation, nuclear, radiative effects is presented. The method is based on the relativistic gauge-invariant (approximation to QED) perturbation theory (PT) and generalized effective field nuclear model with using the optimized one-quasiparticle representation firstly in theory of the hyperfine structure for relativistic atom. The wave function zeroth basis is found from the Dirac equation with potential, which includes the core ab initio potential, the electric and polarization potentials of a nucleus. The correlation corrections of the high orders are taken into account within the Green functions method (with the use of the Feynman diagram's technique). There have taken into account all correlation corrections of the second order and dominated classes of the higher orders diagrams (electrons screening, particle-hole interaction,
\end{abstract}


mass operator iterations). The magnetic inter-electron interaction is accounted in the lowest on $\alpha$ parameter ( $\alpha$ is the fine structure constant), approximation, the self-energy part of the Lamb shift is taken effectively into consideration within the Ivanov-Ivanova non-perturbative procedure, the Lamb shift polarization part - in the generalized Uehling-Serber approximation with accounting for the KällenSabry $\alpha^{2}(\alpha Z)$ and Wichmann-Kroll $\alpha(\alpha Z)^{\mathrm{n}}$ corrections.

Keywords: Relativistic perturbation theory, Heavy ions, Relativistic energy formalism

УДК 539.182

А. В. Глушков, В. Б. Терновский, А. В. Смирнов, А. А. Свинаренко

\section{МЕТОД КАЛИБРОВОЧНО-ИНВАРИАНТНОЙ РЕЛЯТИВИСТСКОЙ ТЕОРИИ ВОЗМУЩЕНИЙ К ОПРЕДЕЛЕНИЮ ЭНЕРГЕТИЧЕСКИХ И СПЕКТРАЛЬНЫХ ХАРАКТЕРИСТИК ТЯЖЕЛЫХ И СВЕРХТЯЖЕЛЫХ АТОМОВ И ИОНОВ: ОБЗОР}

\section{Резюме}

В работе обзорно изложены основы эффективного, последовательного ab initio подхода к релятивистскому вычислению спектров многоэлектронных тяжелых и сверхтяжелых ионов с учетом релятивистских, корреляционных, ядерных, радиационных эффектов. Метод основан на релятивистской калибровочно-инвариантной (КЭД) теории возмущений, обобщенной эффективной полевой модели ядра с использованием оптимизированного одноквазичастичного представления впервые в теории сверхтонкой структуры спектра релятивистского атома. Базис волновых функций нулевого приближения определяется решениями Dirac уравнения с потенциалом, который включает в себя самосогласованный ab initio электронный потенциал, электрический и поляризационный потенциалы ядра. Корреляционные поправки высших порядков учитываются в рамках метода функций Грина (с использованием техники диаграмм Feynman). Учтены все корреляционные поправки второго порядка и доминирующие классы диаграмм высших порядков (экранирование электронов, взаимодействие частицы с дыркой, итерации массового оператора). Магнитное межэлектронное взаимодействие учитывается в низшем по параметру $\alpha$ ( $\alpha$ - постоянная тонкой структуры)приближении, собственно-энергетическая часть лэмбовского сдвига эффективно учитывается в рамках обобщенной непертурбативной процедуры Ivanov-Ivanova, эффект поляризации вакуума лэмбовского сдвига - в приближении Uehling-Serber с учетом поправок Källen-Sabry $\alpha^{2}(\alpha Z)$ и Wichmann-Kroll $\alpha(\alpha Z)^{\mathrm{n}}$ (Z - заряд ядра).

Ключевые слова: Калибровочно-инвариантная релятивистская теория возмущений, Тяжелые ионы, Релятивистский энергетический формализм

О. В. Глушков, В. Б. Терновський, А. В. Смірнов, А. А. Свинаренко

\section{МЕТОД КАЛІБРУВАЛЬНО-ІНВАРІАНТНОЇ РЕЛЯТИВІСТСЬКОЇ ТЕОРІЇ ЗБУРЕНЬ ДО ВИЗНАЧЕННЯ ЕНЕРГЕТИЧНИХ І СПЕКТРАЛЬНИХ ХАРАКТЕРИСТИК ВАЖКИХ І НАДВАЖКИХ АТОМІВ ТА ИОНОВ: ОГЛЯД}

\section{Резюме}

В роботі оглядово викладені основи ефективного, послідовного ab initio підходу до релятивістського обчислення спектрів багатоелектронних важких і надважких іонів з урахуванням 
релятивістських, кореляційних, ядерних, радіаційних ефектів. Метод заснований на релятивістської калібрувально-інваріантної (КЕД) теорії збурень, узагальненої ефективної польової моделі ядра з використанням оптимізованого одноквазічастинкового представлення вперше в теорії надтонкої структури спектру релятивістського атома. Базис хвильових функцій нульового наближення визначається рішеннями Dirac рівняння з потенціалом, який включає в себе самоузгоджений ab initio електронний потенціал, електричний і поляризаційний потенціали ядра. Кореляційні поправки вищих порядків враховуються в рамках методу функцій Гріна (з використанням техніки діаграм Feynman). Враховано всі кореляційні поправки другого порядку і домінуючі класи діаграм вищих порядків (екранування електронів, взаємодія частинки 3 діркою, ітерації масового оператора). Магнітна міжелектронна взаємодія враховується в нижчому за параметром $\alpha$ ( $\alpha$ - стала тонкої структури) наближенні, власне-енергетична частина лембовського зсуву ефективно враховується в рамках узагальненої непертурбативної процедури Ivanov-Ivanova, ефект поляризації вакууму лембовського зсуву - в наближенні UehlingSerber з урахуванням поправок Källen-Sabry $\alpha^{2}(\alpha Z)$ та Wichmann-Kroll $\alpha(\alpha Z)^{\mathrm{n}}(Z$ - заряд ядра).

Ключові слова: Калібрувально-інваріантна релятивістська теорія збурень, Важкі іони, Релятивістський енергетичний формалізм 